\title{
NÍVEIS DE PROTEÍNA BRUTA NA DIETA APÓS O DESMAME E DESEMPENHO EM LEITÕES ${ }^{1}$
}

\author{
TERESINHA MARISA BERTOL ${ }^{2}$ e BENITO GUIMARÃES DE BRITO³
}

\begin{abstract}
RESUMO - Foram comparados três níveis de proteína, com leitões desmamados aos 29 dias de idade, no período de 0 a 15 dias após o desmame. Os tratamentos foram os seguintes: T1- dieta testemunha, com $20 \%$ de proteína bruta (PB); T2 - dieta com $18 \%$ PB; T3 - dieta com 16\% PB. As dietas eram isolisínicas com $1,15 \%$ de lisina. Durante a fase de aleitamento foi fornecida uma dieta pré-inicial a todos os leitões, a partir do sétimo dia de vida. De 16 a 36 dias após o desmame, foi fornecida uma dieta com $18 \%$ de PB a todos os leitões. A redução do nível de $\mathrm{PB}$ da dieta para $18 \%$ ou $16 \%$ não afetou $(\mathrm{P}>0,10)$ o desempenho dos leitões em nenhum dos períodos estudados e reduziu $(\mathrm{P}<0,01)$ a incidência e severidade da diarréia. Concluiu-se que a redução do nível de PB e da proporção do farelo de soja na dieta de leitões desmamados aos 29 dias de idade, acompanhada de suplementação com lisina, por 15 dias após o desmame, pode proporcionar redução na incidência e severidade da diarréia, sem afetar o desempenho.
\end{abstract}

Termos para indexação: diarréia, nutrição.

\section{CRUDE PROTEIN LEVELS IN THE POST-WEANING DIETS AND PERFORMANCE IN PIGLETS}

\begin{abstract}
Three crude protein levels were compared with weaning piglets (29 days of age), in the period from 0 to 15 days post-weaning. The treatments compared were: T1- control diet, $20 \%$ crude protein (CP); T2 - 18\% CP diet; T3 - 16\% CP diet. Diets were isolisinic, containing 1,15\% total lysine. During the weanling phase a pre-starter diet was fed to all piglets, from seventh day of age. An $18 \% \mathrm{CP}$ diet was fed to all piglets, from 16 to 36 days post-weaning. The reduction of $\mathrm{CP}$ level in the diet to $18 \%$ or $16 \%$ did not affect $(\mathrm{P}>0,10)$ the performance of piglets in any of the studied periods and it decreased $(P<0,01)$ the incidence and severity of diarrhea. It was concluded that the reduction in the crude protein level and in the proportion of soybean meal on the diet for piglets weaned at 29 days, fortified with lysine, fed for 15 days post-weaning, decrease the incidence and severity of diarrhea, and not decrease the performance.
\end{abstract}

Index terms: diarrhea, nutrition.

\section{INTRODUÇÃO}

Ao desmame, os leitões apresentam dificuldades em digerir a fração protéica da dieta, em especial as proteínas de origem vegetal. Isso ocorre em virtude dos seguintes fatores: baixa produção de

\footnotetext{
${ }^{1}$ Aceito para publicação em 4 de junho de 1998.

Projeto financiado pelo IAPAR.

${ }^{2}$ Zoot., M.Sc., Embrapa-Centro Nacional de Pesquisa em Suínos e Aves (CNPSA), Caixa Postal 21, CEP 89700-000 Concórdia, SC E-mail: tbertol@cnpsa.embrapa.br

${ }^{3}$ Méd. Vet., BSc., UEL/CIMAPAR - Universidade Estadual de Londrina, Caixa Postal 6001, CEP 86051-970 Londrina, PR. E-mail: brito@uel.br
}

ácido no estômago nas primeiras semanas de vida (Maner et al., 1962; Wilson \& Leibholz, 1981; Bolduan et al., 1988); baixa atividade das enzimas pancreáticas e intestinais (Lindeman et al., 1986; Miller et al., 1986; Owsley et al., 1986); menor solubilidade das proteínas de origem vegetal no meio estomacal; alta capacidade ligadora de ácido das proteínas, provocando elevação no $\mathrm{pH}$ do conteúdo do trato gastrointestinal quando os níveis de proteína da dieta são elevados (Proháska \& Baron, 1980).

Os valores alterados de $\mathrm{pH}$ no conteúdo gastrointestinal favorecem a proliferação da Escherichia coli patogênica no intestino, de acordo com Proháska \& Baron (1980) e Mores et al. (1990). 
Esses autores observaram redução no $\mathrm{pH}$ do conteúdo gastrointestinal e na quantidade de $E$. coli patogênica no intestino com a redução do nível de proteína da dieta. Mores et al. (1990), também observaram redução na ocorrência de diarréia em leitões desmamados com 35 dias de idade, recebendo dietas com $16 \%$ de PB, em comparação com $20 \%$ de PB. Portanto, é possível manipular o ambiente intestinal por meio da composição da dieta. No entanto, a redução excessiva do nível de proteína pode prejudicar o desempenho dos leitões.

Hansen et al. (1993) observaram que houve redução do desempenho em leitões desmamados com 28 dias de idade, quando receberam uma dieta que continha $15 \%$ de proteína, suplementada com lisina, metionina e treonina. A redução do desempenho foi atribuída pelos autores a uma deficiência de $\mathrm{N}$ não específico. Além disso, os autores concluíram que dietas com $17 \%$ de PB suplementadas com lisina, metionina e treonina proporcionaram desempenho semelhante ao obtido com dietas contendo $21 \%$ de $\mathrm{PB}$, mantendo-se entre ambas os mesmos níveis dos aminoácidos citados acima.

A presença de proteínas não digeridas ou aminoácidos na porção terminal do íleo e no intestino grosso pode estimular o desenvolvimento da flora bacteriana proteolítica, a qual produz ácidos e aminas. Estes, causam irritação na mucosa intestinal, provocando o aparecimento de diarréia (Holland, 1990).

A presença de substâncias antigênicas na dieta de leitões, principalmente no farelo de soja, representada, pelas proteínas glicinina e $\beta$-conglicinina, provoca uma reação de hipersensibilidade transitória, com alterações na estrutura da parede intestinal (Miller et al., 1984; Li et al., 1990, 1991). Tais alterações resultam em redução do tamanho das vilosidades com diminuição da superfície absortiva do intestino, redução da atividade das enzimas intestinais (Miller et al., 1984; Hampson, 1986) e desequilíbrio entre a secreção e absorção de água e eletrólitos (Miller et al., 1984). Desta forma, altos níveis de farelo de soja na dieta de leitões após o desmame contribuem para um aumento da ocorrência dos distúrbios entéricos e para a redução da taxa de crescimento (Bourne \& Newby, 1981; Hankins et al., 1992).
O objetivo deste estudo foi verificar o efeito da redução do nível de proteína e da redução da proporção do farelo de soja da dieta, sobre o desempenho e a ocorrência de diarréia pós-desmame em leitões.

\section{MATERIAL E MÉTODOS}

O experimento foi conduzido na granja de suínos da Estação Experimental do IAPAR, em Pato Branco, PR. Foram utilizados 89 leitões mestiços Duroc x Large White, desmamados com $29 \pm 1$ dia de idade, pesando em média $7,94 \pm 0,74 \mathrm{~kg}$ de peso vivo.

Foram comparadas três dietas, com os seguintes níveis de proteína bruta $(\mathrm{PB})$, no período de 0 a 15 dias após o desmame: Tratamento 1 (T1) - dieta testemunha, com $20 \%$ de PB; Tratamento 2 (T2) - dieta com $18 \%$ de PB; Tratamento 3 (T3) - dieta com $16 \%$ de PB.

As dietas eram isolisínicas $(1,15 \%)$ e foram formuladas de acordo com as exigências do National Research Council (1988) (Tabela 1). Durante a fase de aleitamento foi fornecida uma dieta pré-inicial a todos os leitões a partir

TABELA 1. Composição percentual das dietas utilizadas de 0 a 15 dias do período experimental.

\begin{tabular}{lrrr}
\hline Ingredientes & \multicolumn{3}{c}{ Níveis de proteína bruta (\%) } \\
\cline { 2 - 4 } & \multicolumn{1}{c}{20} & 18 & \multicolumn{1}{c}{16} \\
\hline Milho & 52,02 & 58,33 & 64,46 \\
Farelo de soja & 31,62 & 25,04 & 18,66 \\
Soro de leite em pó & 10,00 & 10,00 & 10,00 \\
Farinha de carne & 5,00 & 5,00 & 5,00 \\
Fosfato bicálcico & 0,05 & 0,18 & 0,31 \\
Calcário & 0,41 & 0,39 & 0,36 \\
Óxido de zinco & 0,39 & 0,39 & 0,39 \\
L-Lisina (98\%) & 0,04 & 0,20 & 0,35 \\
Premix mineral e vitamínico & 0,37 & 0,37 & 0,37 \\
Sal & 0,10 & 0,10 & 0,10 \\
\hline Total & 100,00 & 100,00 & 100,00 \\
\hline Composição calculada & \multicolumn{3}{|}{} \\
\hline EM (kcal/kg) & 3.220 & 3.224 & 3.228 \\
PB (\%) & 20 & 18 & 16 \\
Lisina (\%) & 1,15 & 1,15 & 1,15 \\
Metionina+cistina (\%) & 0,63 & 0,58 & 0,52 \\
Treonina & 0,83 & 0,74 & 0,65 \\
Triptofano & 0,27 & 0,23 & 0,20 \\
Cálcio (\%) & 0,80 & 0,80 & 0,80 \\
Fósforo total (\%) & 0,65 & 0,65 & 0,65 \\
Zinco (ppm) & 3.000 & 3.000 & 3.000 \\
\hline
\end{tabular}


do sétimo dia de vida. De 16 a 36 dias do período experimental foi fornecida uma dieta única a todos os leitões, baseada em milho e farelo de soja, acrescida de vitaminas, minerais e aditivos, sem a inclusão de produtos lácteos. Essa dieta apresentava $18 \%$ de PB, $0,95 \%$ de lisina, $0,70 \%$ de cálcio, $0,60 \%$ de fósforo total e $1.500 \mathrm{ppm}$ de zinco. As rações e a água foram fornecidas à vontade a todos os animais, em comedouros e bebedouros automáticos.

Os animais foram distribuídos em blocos casualizados de acordo com o peso inicial, em oito repetições por tratamento, e cada repetição (baia) contendo três ou quatro leitões de ambos os sexos, distribuídos em número mais aproximado possível entre os tratamentos. No total, havia 29 leitões (15 machos e 14 fêmeas) no T1; 30 leitões (15 machos e 15 fêmeas) no T2; e 30 leitões (17 machos e 13 fêmeas) no T3.

Os dados de desempenho, representados pelo ganho de peso médio diário (GPMD), consumo de ração médio diário (CRMD), conversão alimentar (CA), peso médio (PM) aos 15 dias após o desmame e PM aos 36 dias, foram submetidos à análise de variância mediante procedimento GLM (SAS, 1987). A análise de variância foi feita de acordo com o seguinte modelo matemático:

$\mathrm{Y}_{\mathrm{ij}}=\mu+\mathrm{P}_{\mathrm{i}}+\mathrm{B}_{\mathrm{j}}+\mathrm{e}_{\mathrm{ij}}$,

onde:

$\mathrm{Y}_{\mathrm{ij}}=$ observação da variável no nível de proteína i, bloco j; $\mu=$ média geral;

$\mathrm{P}_{\mathrm{i}}=$ efeito dos níveis de proteína $(\mathrm{i}=1,2,3)$;

$B_{j}=$ efeito de bloco (peso inicial) $(j=1,2, \ldots, 8) ; e$

$\mathrm{e}_{\mathrm{ij}}=$ erro aleatório associado a cada observação.

Com os dados individuais de GPMD foi realizada outra análise estatística, também pelo procedimento GLM (SAS, 1987), incluindo-se o efeito da diarréia no modelo matemático:

$\mathrm{Y}_{\mathrm{ijk}}=\mu+\mathrm{P}_{\mathrm{i}}+\mathrm{D}_{\mathrm{j}}+(\mathrm{PD})_{\mathrm{ij}}+\mathrm{e}_{\mathrm{ijk}}$,

onde:

$\mathrm{Y}_{\mathrm{ijk}}=$ observação da variável no nível de proteína i, incidência ou não de diarréia j, repetição k;

$\mu=$ média geral;

$\mathrm{P}_{\mathrm{i}}=$ efeito dos níveis de proteína $(\mathrm{i}=1,2,3)$;

$\mathrm{D}_{\mathrm{j}}=$ efeito da diarréia $(\mathrm{j}=1,2)$;

$(\mathrm{PD})_{\mathrm{ij}}=$ efeito da interação entre nível de proteína e diarréia; e

$\mathrm{e}_{\mathrm{ijk}}=$ erro aleatório associado a cada observação.

A incidência de diarréia (ID) foi avaliada por observação diária de todos os animais, de acordo com o seguinte escore: 0 - fezes normais, 1 - fezes amolecidas, 2 - fezes líquidas, 3 - fezes líquidas com desidratacão do animal. Esses dados foram agrupados, somados os escores $0+1$ (sem diarréia) e $2+3$ (com diarréia) dentro de cada tratamento e submetidos ao teste $\chi^{2}$ (Pimentel-Gomes, 1990).

Em todas as análises estatísticas efetuadas, o nível máximo de significância considerado foi o de $10 \%$.

\section{RESULTADOS E DISCUSSÃO}

$\mathrm{Na}$ análise geral dos dados de desempenho, observa-se que a redução do nível de PB da dieta não afetou $(\mathrm{P}>0,10)$ o desempenho dos leitões em nenhum dos períodos avaliados (Tabela 2). Isto foi evidenciado pelo fato de não ter havido diferença entre os tratamentos sobre o GPMD, CRMD, CA e PM aos 15 ou 36 dias após o desmame. No entanto, a diarréia afetou $(\mathrm{P}<0,013)$ o GPMD em todas as fases, conforme pode ser observado na Tabela 3 .

Comparando-se o GPMD entre os leitões que apresentaram diarréia e os que não apresentaram, dentro de cada nível de PB, observa-se que o distúrbio afetou negativamente $(\mathrm{P}<0,05)$ o GPMD na fase de fornecimento das dietas, nos níveis $20 \%$ e $18 \%$ de PB (Tabela 4). No período subseqüente e no período total, o GPMD foi afetado pela diarréia somente no nível $20 \%$ de PB.

$\mathrm{Na}$ comparação entre os diferentes níveis de $\mathrm{PB}$, dentro dos grupos de leitões que tiveram ou não diarréia (Tabela 5), observou-se que a redução do nível de $\mathrm{PB}$ da dieta para $18 \%$ ou $16 \%$ provocou redução $(\mathrm{P}<0,02)$ no GPMD no período de 16 a 36 dias após o desmame e no período total do experimento nos leitões que não tiveram diarréia. Naqueles que apresentaram diarréia por pelo menos um dia, o GPMD não foi significativamente afetado pela redução do nível de $\mathrm{PB}$ da dieta, em nenhum dos períodos avaliados.

Houve redução $(\mathrm{P}<0,01)$ da ID e da severidade da diarréia nos níveis $18 \%$ e $16 \%$ de PB em relação ao nível 20\% (Tabelas 6 e 7). Enquanto $83 \%$ dos leitões do nível $20 \%$ apresentaram diarréia por pelo menos um dia no período avaliado, $53 \%$ e $63 \%$ dos leitões apresentaram diarréia nos níveis $18 \%$ e 16\%, respectivamente (Tabela 6). Entre os leitões que apresentaram diarréia, o número médio de dias com o distúrbio foi $3,25,1,73$ e 1,37 , nos níveis $20 \%, 18 \%$ e $16 \%$ de $\mathrm{PB}$, respectivamente (Tabela 7).

A ausência de resposta nos dados de desempenho, com a redução do nível de proteína da dieta, demonstra que é possível fornecer baixos níveis de 
TABELA 2. Efeito dos níveis de proteína bruta da dieta sobre o desempenho dos leitões de 0 a 15 dias, 16 a 36 dias e 0 a 36 dias após o desmame.

\begin{tabular}{|c|c|c|c|c|}
\hline \multirow[t]{2}{*}{ Variáveis $^{1}$} & \multicolumn{3}{|c|}{ Níveis de proteína bruta $(\%)$} & \multirow[t]{2}{*}{$\mathrm{P}^{2}$} \\
\hline & 20 & 18 & 16 & \\
\hline \multicolumn{5}{|c|}{$0-15$ dias } \\
\hline PMI (kg) & $7,95 \pm 0,71^{3}$ & $7,93 \pm 0,74$ & $7,94 \pm 0,77$ & 1,00 \\
\hline GPMD (g) & $155 \pm 33$ & $163 \pm 51$ & $159 \pm 34$ & 0,85 \\
\hline CRMD (g) & $333 \pm 46$ & $360 \pm 53$ & $360 \pm 50$ & 0,27 \\
\hline $\mathrm{CA}$ & $2,26 \pm 0,62$ & $2,32 \pm 0,52$ & $2,29 \pm 0,26$ & 0,95 \\
\hline PM 15 dias $(\mathrm{kg})$ & $10,27 \pm 0,88$ & $10,38 \pm 1,24$ & $10,35 \pm 0,95$ & 0,90 \\
\hline \multicolumn{5}{|c|}{$16-36$ dias } \\
\hline GPMD (g) & $456 \pm 65$ & $429 \pm 59$ & $443 \pm 51$ & 0,48 \\
\hline CRMD (g) & $924 \pm 141$ & $888 \pm 124$ & $911 \pm 104$ & 0,84 \\
\hline $\mathrm{CA}$ & $2,04 \pm 0,22$ & $2,07 \pm 0,10$ & $2,06 \pm 0,07$ & 0,89 \\
\hline \multicolumn{5}{|c|}{$0-36$ dias } \\
\hline GPMD (g) & $331 \pm 50$ & $318 \pm 49$ & $325 \pm 37$ & 0,76 \\
\hline CRMD (g) & $677 \pm 78$ & $668 \pm 93$ & $681 \pm 79$ & 0,94 \\
\hline $\mathrm{CA}$ & $2,07 \pm 0,22$ & $2,11 \pm 0,11$ & $2,10 \pm 0,07$ & 0,81 \\
\hline PM 36 dias (kg) & $19,86 \pm 2,01$ & $19,38 \pm 2,27$ & $19,66 \pm 1,91$ & 0,74 \\
\hline
\end{tabular}

TABELA 3. Efeito da diarréia sobre o ganho de peso médio diário (GPMD) (g) dos leitões de 0 a 15 dias, 16 a 36 dias e 0 a 36 dias após o desmame 1 .

\begin{tabular}{cccc}
\hline \multirow{2}{*}{ Período (dias) } & \multicolumn{2}{c}{ Diarréia } & $\mathrm{P}^{3}$ \\
\cline { 2 - 3 } & Não & $\operatorname{Sim}^{2}$ & \\
\hline $0-15$ & $187 \mathrm{a}$ & $148 \mathrm{~b}$ & 0,006 \\
$16-36$ & $485 \mathrm{a}$ & $432 \mathrm{~b}$ & 0,013 \\
$0-36$ & $283 \mathrm{a}$ & $252 \mathrm{~b}$ & 0,013 \\
\hline
\end{tabular}

${ }^{1}$ Médias com letras diferentes na mesma linha diferem pelo teste $\mathrm{F}$.

2 Apresentaram diarréia por pelo menos um dia.

${ }^{3}$ Níveis de significância pelo teste $\mathrm{F}$.

PB (até 16\%) por períodos curtos na dieta de desmame dos leitões, desde que suplementadas com L-lisina para suprir os níveis mínimos necessários. Por sua vez, Hansen et al. (1993) observaram que em dietas com $15 \%$ ou $17 \%$ de PB suplementadas para manter $1,15 \%$ de lisina total e $0,95 \%$ de lisina digestível, a treonina e a metionina são limitantes para leitões desmamados com 28 dias de idade. As-
TABELA 4. Efeito da diarréia dentro de cada nível de proteína bruta da dieta sobre o ganho de peso médio diário (GPMD) (g) dos leitões de 0 a 15 dias, 16 a 36 dias e 0 a 36 dias após o desmame'.

\begin{tabular}{ccccc}
\hline Níveis de proteína & Diarréia & \multicolumn{4}{c}{ Período (dias) } \\
\cline { 3 - 5 } bruta (\%) & & $0-15$ & $16-36$ & $0-36$ \\
\hline \multirow{2}{*}{20} & Não & $202 \mathrm{a}$ & $555 \mathrm{a}$ & $324 \mathrm{a}$ \\
& Sim $^{2}$ & $142 \mathrm{~b}$ & $433 \mathrm{~b}$ & $252 \mathrm{~b}$ \\
\multirow{2}{*}{18} & Não & $189 \mathrm{a}$ & $453 \mathrm{a}$ & $264 \mathrm{a}$ \\
& Sim & $147 \mathrm{~b}$ & $415 \mathrm{a}$ & $242 \mathrm{a}$ \\
\multirow{2}{*}{16} & Não & $171 \mathrm{a}$ & $448 \mathrm{a}$ & $261 \mathrm{a}$ \\
& Sim & $157 \mathrm{a}$ & $449 \mathrm{a}$ & $262 \mathrm{a}$ \\
\hline
\end{tabular}

${ }^{1}$ Médias com letras diferentes na mesma coluna, dentro de cada nível de proteína, diferem $(\mathrm{P}<0,05)$ pelo teste $\mathrm{t}$.

2 Apresentaram diarréia por pelo menos um dia.

sim, quando a dieta que continha $17 \%$ de $\mathrm{PB}$ foi suplementada também com metionina e treonina, verificou-se desempenho semelhante ao obtido com a dieta que continha $21 \%$ de PB. Porém, o 
TABELA 5. Efeito dos níveis de proteína bruta da dieta, de 0 a 15 dias, 16 a 36 dias e 0 a 36 dias após o desmame, sobre o ganho de peso médio diário (GPMD) (g) dos leitões que apresentaram ou não diarréia ${ }^{1}$.

\begin{tabular}{lcccc}
\hline Diarréia & $\begin{array}{c}\text { Níveis de } \\
\text { proteína } \\
\text { bruta (\%) }\end{array}$ & \multicolumn{3}{c}{ Período (dias) } \\
\cline { 3 - 5 } & 20 & $202 \mathrm{a}$ & $555 \mathrm{a}$ & $324 \mathrm{a}$ \\
\hline \multirow{2}{*}{ Não } & 18 & $189 \mathrm{a}$ & $453 \mathrm{~b}$ & $264 \mathrm{~b}$ \\
& 16 & $171 \mathrm{a}$ & $448 \mathrm{~b}$ & $261 \mathrm{~b}$ \\
& 20 & $142 \mathrm{a}$ & $433 \mathrm{a}$ & $252 \mathrm{a}$ \\
$\mathrm{Sim}^{2}$ & 18 & $147 \mathrm{a}$ & $415 \mathrm{a}$ & $242 \mathrm{a}$ \\
& 16 & $157 \mathrm{a}$ & $449 \mathrm{a}$ & $262 \mathrm{a}$ \\
\hline
\end{tabular}

${ }^{1}$ Médias com letras diferentes na mesma coluna, dentro de cada categoria de diarréia, diferem $(\mathrm{P}<0,02)$ pelo teste $\mathrm{t}$.

2 Apresentaram diarréia por pelo menos um dia.

TABELA 6. Efeito do nível de proteína bruta da dieta sobre o número de leitões que apresentaram diarréia de 0 a 21 dias após 0 desmame ${ }^{1}$.

\begin{tabular}{|c|c|c|c|}
\hline $\begin{array}{l}\text { Níveis de } \\
\text { proteína } \\
\text { bruta }(\%)\end{array}$ & $\begin{array}{l}\text { Número } \\
\text { total } \\
\text { de leitões }\end{array}$ & $\begin{array}{c}\text { Sem diarréia } \\
\text { durante } \\
\text { todo o } \\
\text { período }^{2}\end{array}$ & $\begin{array}{c}\text { Com diarréia } \\
\text { por pelo } \\
\text { menos } \\
\text { um dia }^{3}\end{array}$ \\
\hline
\end{tabular}

\begin{tabular}{rrrr}
\hline 20 & 29 & $5 \mathrm{a}$ & $24 \mathrm{a}$ \\
18 & 30 & $14 \mathrm{~b}$ & $16 \mathrm{~b}$ \\
16 & 30 & $11 \mathrm{~b}$ & $19 \mathrm{~b}$ \\
\hline
\end{tabular}

1 Valores com letras diferentes na mesma coluna, diferem $(\mathrm{P}<0,01)$, pelo teste $\chi^{2}$.

2 Escore $0+1$

3 Escore $2+3$.

mesmo não ocorreu com a dieta contendo $15 \%$ de PB. As dietas de Hansen et al. (1993) foram fornecidas durante 28 dias, ao passo que neste experimento por 15 dias apenas. Se o período de fornecimento das dietas fosse o mesmo (28 dias) em
TABELA 7. Efeito do nível de proteína bruta da dieta sobre o número de leitões que apresentaram diarréia de 0 a 21 dias após 0 desmame, de acordo com o tempo de duração da diarréia ${ }^{1}$.

\begin{tabular}{cccc}
\hline Duração da diarréia & \multicolumn{3}{c}{ Níveis de proteína bruta (\%) } \\
\cline { 2 - 4 } (dias) $^{2}$ & 20 & 18 & 16 \\
\hline 0 & $5 \mathrm{a}$ & $14 \mathrm{~b}$ & $11 \mathrm{~b}$ \\
$1-2$ & $10 \mathrm{~b}$ & $8 \mathrm{a}$ & $12 \mathrm{c}$ \\
$3-5$ & $10 \mathrm{a}$ & $6 \mathrm{~b}$ & $7 \mathrm{~b}$ \\
$6-8$ & $4 \mathrm{a}$ & $2 \mathrm{~b}$ & $0 \mathrm{~b}$ \\
\hline
\end{tabular}

${ }^{1}$ Valores com letras diferentes na mesma linha, diferem $(\mathrm{P}<0,01)$, pelo teste $\chi^{2}$.

2 Escore $2+3$

ambos os experimentos, é possível que neste também houvesse redução de desempenho por deficiência de metionina+cistina e/ou treonina, pois com $16 \%$ de PB os níveis desses aminoácidos estavam um pouco abaixo do recomendado pelo National Research Council (1988). Possivelmente esta seja uma das causas da redução observada no GPMD com a redução dos níveis de $\mathrm{PB}$, nos leitões que não apresentaram diarréia. Outra causa poderia ser uma maior resposta por parte dos leitões que não tiveram diarréia ao maior nível de lisina da dieta, em razão de um menor nível de ativação do sistema imune. Leitões criados em condições de baixa ativação do sistema imune respondem a níveis mais elevados de nutrientes na dieta e apresentam maior taxa de crescimento, possivelmente em decorrência de um elevado nível de hormônio de crescimento ou fatores de crescimento, ou de alteração da resposta das células aos fatores de crescimento (Wiseman et al., 1994).

A redução do ganho de peso nos leitões que não tiveram diarréia e que receberam os níveis mais baixos de proteína foi parcialmente compensada por um ligeiro aumento (não significativo) do ganho de peso dos leitões que apresentaram diarréia nos mesmos tratamentos. Desta forma, houve apenas uma pequena e não significativa diferença no ganho de peso de todos os leitões entre os tratamentos.

A semelhança no ganho de peso entre os leitões que apresentaram diarréia e os que não apresenta- 
ram nos níveis $18 \%$ e $16 \%$ de $\mathrm{PB}$ e a redução no ganho de peso dos leitões que tiveram diarréia no nível 20\% de PB indicam que o efeito da diarréia sobre o ganho de peso é dependente de sua severidade (dias de duração).

A redução na ID observada nos leitões que receberam as dietas com os dois níveis mais baixos de PB está de acordo com os resultados encontrados por Proháska \& Baron (1980) e por Mores et al. (1990). Tais resultados indicam um possível efeito de redução do tamponamento do $\mathrm{pH}$ do conteúdo gastrointestinal em função da menor capacidade ligadora de ácido das dietas que continham os níveis mais baixos de $\mathrm{PB}$, e menor agressão à parede intestinal causada pela redução da proporção do farelo de soja na dieta. Assim, a redução do nível de PB da dieta é um recurso que pode ser utilizado para auxiliar na redução do $\mathrm{pH}$ do trato gastrointestinal, prevenindo a ocorrência de diarréia. Foi comprovado por Mores et al. (1990), que a redução do nível de PB tem efeito aditivo com os ácidos orgânicos na redução do $\mathrm{pH}$ do conteúdo gastrointestinal e na redução da ID.

Tem sido observado que o farelo de soja provoca aumento no título de anticorpos IgG anti-soja no soro, em leitões precocemente desmamados (Li et al., 1990; 1991). Tal fato tem sido associado a danos nas vilosidades intestinais, com redução na performance de crescimento e aumento na ID. É possível que a redução na incidência e severidade da diarréia observada nos tratamentos com os níveis mais baixos de PB tenha ocorrido também por causa de uma menor agressão à parede intestinal, com a redução da proporção do farelo de soja nessas dietas.

\section{CONCLUSÕES}

1. A redução do nível de proteína bruta da dieta de leitões desmamados aos 29 dias de idade para $18 \%$ ou $16 \%$, bem como a redução da proporção do farelo de soja, acompanhada de suplementação com lisina, durante 15 dias após o desmame, proporciona redução na incidência e na severidade da diarréia, sem afetar o desempenho durante toda a fase de creche.

2. A diarréia afeta o ganho de peso dos leitões após o desmame.

\section{REFERÊNCIAS}

BOLDUAN, G.; JUNG, H.; SCHNABEL, E.; SCHNEIDER, R. Recent advances in the nutrition of weaner piglets. Pig News and Information, v.9, n.4, p.381-385, Dec. 1988.

BOURNE, F.J.; NEWBY, T.J. Mucosal immunity in the pig. Pig News and Information, v.2, n.2, p.141144, 1981.

HAMPSON, D.J. Alterations in piglet small intestinal structure at weaning. Research in Veterinary Science, v.40, n.1, p.32-40, Jan. 1986.

HANKINS, C.C.; NOLAND, P.R.; BURKS JUNIOR, A.W.; CONNAUGHTON, C.; COCKRELL, G.; METZ, C.L. Effect of soy protein ingestion on total and specific immunoglobulin $\mathrm{G}$ concentrations in neonatal porcine serum measured by enzyme-linked immunoabsorbent assay. Journal of Animal Science, Champaign, v.70, n.14, p.3096-3101, Oct. 1992.

HANSEN, J.A.; KNABE, D.A.; BURGOON, K.G. Amino acid supplementation of low-protein sorghum-soybean meal diets for 5- to 20- kilogram swine. Journal of Animal Science, Champaign, v.71, n.2, p.452-458, Feb. 1993.

HOLLAND, R.E. Some infectious causes of diarrhoea in young farm animals. Clinical Microbiology Reviews, v.3, p.345-375, 1990.

LI, D.F.; NELSSEN, J.L.; REDDY, P.G.; BLECHA, F.; HANCOCK, J.D.; ALLEE, G.L.; GOODBAND, R.D.; KLEMM, R.D. Transient hypersensitivity to soybean meal in the early-weaned pig. Journal of Animal Science, Champaign, v.68, n.6, p.17901799, June 1990

LI, D.F.; NELSSEN, J.L.; REDDY, P.G.; BLECHA, F.; KLEMM, R.D.; GIESTING, D.W.; HANCOCK, J.D.; ALLEE, G.L.; GOODBAND, R.D. Measuring suitability of soybean products for early weaned pigs with immunological criteria. Journal of Animal Science, Champaign, v.69, n.8, p.3299-3307, Aug. 1991.

LINDEMAN, M.D.; CORNELIUS, S.G.; KANDELGY, S.M.; MOSER, R.L.; PETTIGREW, J.E. Effect of age, weaning and diet on digestive enzyme levels in the piglets. Journal of Animal Science, Champaign, v.62, n.5, p.1298-1307, May 1986. 
MANER, J.H.; POND, W.S.; LOOSLE, J.E.; LOWREY, R.S. Effect of isolated soybean protein and casein on gastric $\mathrm{pH}$ and rate of passage of food residues in baby pigs. Journal of Animal Science, Champaign, v.21, n.1, p.49-52, Feb. 1962.

MILLER, B.G.; NEWBY, T.J.; STOKES, C.R.; BOURNE, F.J. Influence of diet on post weaning malabsorption and diarrhoea in the pig. Research in Veterinary Science, v.36, p.187-193, 1984

MILLER, B.G.; JAMES, P.S.; SMITH, M.W.; BOURNE, F.J. Effect of weaning on the capacity of pig intestinal villi to digest and absorb nutrients. Journal of Agricultural Science, Cambridge, v.107, n.3, p.579589, Dec. 1986.

MORES, N.; MARQUES, J.L.L.; SOBESTIANSKY, J.; OLIVEIRA, A .; COELHO, L.S.S. Influência do nível protéico e/ou da acidificação da dieta sobre a diarréia pós-desmame em leitões causada por Escherichia coli. Pesquisa Veterinária Brasileira, Rio de Janeiro, v.10, n.3/4, p.85-88, Jul./Dez. 1990.

NATIONAL RESEARCH COUNCIL. Nutrient requirements of domestic animals. Washington DC: National Academy of Science, 1988. 64p. (Nutrient Requirements of Swine, 2).
OWSLEY, W.F.; ORR, D.E.; TRIBBLE, L.F. Effects of age and diet on the development of the pancreas and the syntesis and secretion of pancreatic enzymes in the young pig. Journal of Animal Science, Champaign, v.63, n.2, p.497-504, Aug. 1986.

PIMENTEL-GOMES, F. Curso de estatística experimental. Piracicaba: Nobel, 1990. 468p.

PROHÁSKA, L.; BARON, F. The predisposing role of high dietary protein supplies in enteropathogenic $E$. coli infections of weaned pigs. Zentralblatt für Veterinaermedizin A, Berlin, v.27, n.3, p.222-232, 1980.

SAS INSTITUTE (Cary, NC). Guide for personal computers. Version 6. Cary, NC, 1987. 1028p.

WILSON, R.H.; LEIBHOLZ, J. Digestion in the between 7 and $35 \mathrm{~d}$ of age: 3 . The digestion of nitrogen in pigs given milk and soya-bean proteins. British Journal of Nutrition, London, v.45, p.337-346, 1981.

WISEMAN, B.; MOLITOR, T.; WHITE, M.; MORRISON, B.; DIAL, G. Health and immunological aspects of early weaning. In: ANNUAL MEETING OF AMERICAN ASSOCIATION OF SWINE PRACTITIONERS, 25., 1994, Chicago, Ilinois. Proceedings... Chicago: AASP, 1994. p.5-8. 